\title{
Compact Circularly Polarized Composite Cavity-Backed Crossed Dipole for GPS Applications
}

\author{
Son Xuat $\mathrm{Ta}^{1} \cdot$ Jae Jin $\mathrm{Han}^{1,2} \cdot \mathrm{Ikmo} \mathrm{Park}^{1}$
}

\begin{abstract}
In this paper, we present a circularly polarized (CP) composite cavity-backed crossed dipole antenna for global positioning system (GPS) applications. We produce the CP radiation by crossing two dipoles through a $90^{\circ}$ phase delay line of a vacant-quarter printed ring, which also has a broadband impedance matching characteristic. Two techniques, insertion of meander lines in the dipole arm and arrowhead-shaped trace at its end, are employed to reduce the sizes of the primary radiation element. The compact radiator is backed by a cavity reflector to achieve a wide CP radiation beamwidth. The proposed antenna exhibits a measured bandwidth of $1.450 \sim 1.656 \mathrm{GHz}$ for a voltage standing wave ratio (VSWR) $<2$ and $1.555 \sim 1.605 \mathrm{GHz}$ for $\mathrm{AR}<3-\mathrm{dB}$. At $1.575 \mathrm{GHz}$, the antenna has a gain of $7 \mathrm{dBic}$, a frontto-back ratio of $27 \mathrm{~dB}, \mathrm{AR}$ of $1.18 \mathrm{~dB}$, and $3-\mathrm{dB}$ AR beamwidths of $130^{\circ}$ and $132^{\circ}$ in the $\mathrm{x}-\mathrm{z}$ and $\mathrm{y}-\mathrm{z}$ planes, respectively.
\end{abstract}

Key words: Wide-Beamwidth, Circular Polarization, Crossed Dipole, Meander Line, Arrowhead Shaped Shape, Phase Delay Line, Cavity-Backed Reflector.

\section{I . Introduction}

The global positioning system (GPS) is the most popular member of Global Navigation Satellite Systems (GNSS) that provide location and time information about user in anywhere on the Earth [1]. GPS universally utilizes circularly polarized (CP) radiation due to Faraday rotation when signals pass through the ionosphere. In particular, GPS receiver antennas are required to have right-hand circular polarization (RHCP), a wide 3-dB axial ratio beamwidth that faces the sky, and a high front-to-back ratio to avoid interference from the ground. Various types of CP antennas were introduced to operate at GPS bands, including the microstrip antennas [2], [3], near-field resonant parasitic antennas [4], [5], crossed dipole antennas [6], and pinwheel-shaped planar monopole antennas [7]. However, most of these designs essentially focused on the $\mathrm{CP}$ generation or 3-dB AR bandwidth enhancement rather than improvement of the 3-dB AR beamwidth. Recently, several techniques for widening the $\mathrm{CP}$ radiation beamwidth have been reported, such as a pyramidal ground structure with a par- tially enclosed flat conducting wall [8], an auxiliary radiator [9], applying higher order modes [10], loading gaps and stubs on the patch [11], and a microstrip-monopole combination [12].

In this paper, a compact composite cavity-backed crossed dipole is introduced as a simple way to improve the CP radiation beamwidth. The proposed design utilizes a cavity-backed reflector not only to render a unidirectional pattern but also to improve the $\mathrm{CP}$ radiation in terms of 3-dB AR bandwidth and beamwidth. For a compact size of radiator, two techniques are employed: insertion of meander lines in the dipole arm and shaping of the dipole arm end into arrowhead [4]. A vacantquarter printed ring is used as $90^{\circ}$ phase delay line of crossed dipoles to produce $\mathrm{CP}$ radiation [6].

\section{II . Antenna Design and Characteristics}

Fig. 1 shows the geometry of the compact composite cavity-backed crossed dipole. The antenna was comprised of two printed dipoles, a cavity reflector, and a coaxial line. The cavity was a rectangular box with a di-

Manuscript received January 7, 2013 ; Revised February 25, 2013 ; Accepted February 26, 2013. (ID No. 20130107-002J)

${ }^{1}$ Department of Electrical and Computer Engineering, Ajou University, Suwon, Korea.

${ }^{2}$ Danam Systems, Dongan-gu, Anyang, Korea.

Corresponding Author : Ikmo Park (e-mail : ipark@ajou.ac.kr)

This is an Open-Access article distributed under the terms of the Creative Commons Attribution Non-Commercial License (http://creativecommons.org/licenses/ by-nc/3.0) which permits unrestricted non-commercial use, distribution, and reproduction in any medium, provided the original work is properly cited. 


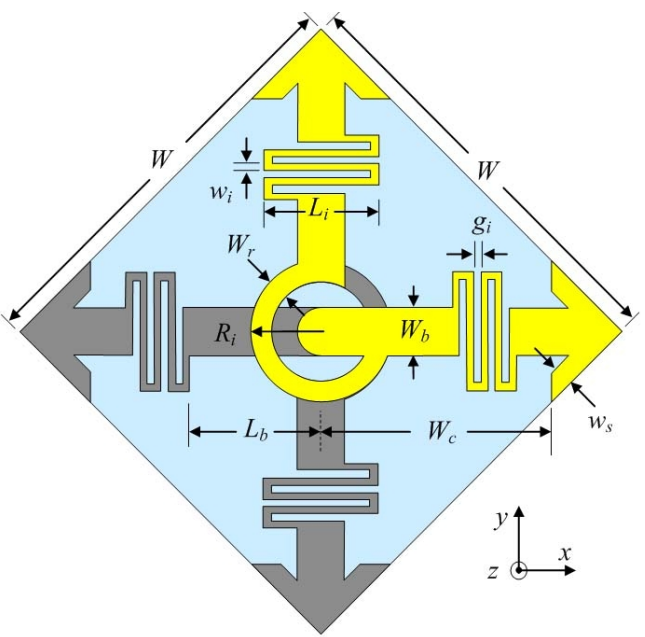

(a) Printed crossed arrowhead-dipoles with 4 meander-lines

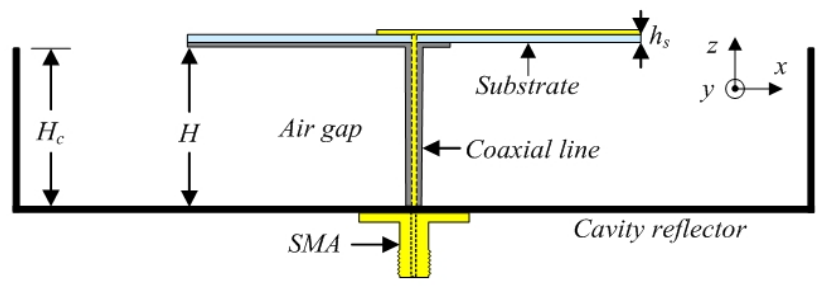

(b) Side views with a cavity-backed reflector

Fig. 1. Geometry of the proposed antenna.

mension of $90 \times 90 \mathrm{~mm}$ and a height of $H_{c}=30 \mathrm{~mm}$. The printed dipoles were placed at the center of the cavity and suspended at a height of $H=30 \mathrm{~mm}$ from the bottom of the reflector. The coaxial line was punctured through the cavity to feed the printed dipoles. The dipoles were designed on both sides of a $42 \times 42 \mathrm{~mm}$ Rogers RO4003 substrate with a permittivity of 3.38 , a loss tangent of 0.0027 , and a thickness of $0.2032 \mathrm{~mm}$. The outer conductor of coaxial line was connected to the arms on bottom side of the substrate. The inner conductor of the feedline was extended through the substrate and connected to the arms on top side. Each dipole arm contained a meander line and an arrowhead-shaped end. The dipoles were crossed through a vacant-quarter printed ring that was acted as the $90^{\circ}$ phase delay line. The meander line was started at $L_{b}$ from the center, with a trace width of $w_{i}$, and their segments had a gap size of $g_{i}$ and a length of $L_{i}$. The ANSYS-Ansoft high-frequency structure simulator (HFSS) was used to investigate the antenna characteristics. The optimized antenna design parameters were chosen for the minimum $A R$ at $1.575 \mathrm{GHz}$ and the wide $\mathrm{CP}$ radiation beamwidth, as follows: $W=42 \mathrm{~mm}, W_{c}=22.5 \mathrm{~mm}, R_{i}=5.4 \mathrm{~mm}, W_{r}=0.8$ $\mathrm{mm}, W_{b}=4 \mathrm{~mm}, L_{b}=11 \mathrm{~mm}, L_{i}=10 \mathrm{~mm}, g_{i}=0.4 \mathrm{~mm}, w_{i}$ $=0.8 \mathrm{~mm}, w_{s}=1.6 \mathrm{~mm}, h_{s}=0.2032 \mathrm{~mm}, H_{c}=30 \mathrm{~mm}$, and $H=30 \mathrm{~mm}$.

Fig. 2(a) illustrates the process of antenna design; the

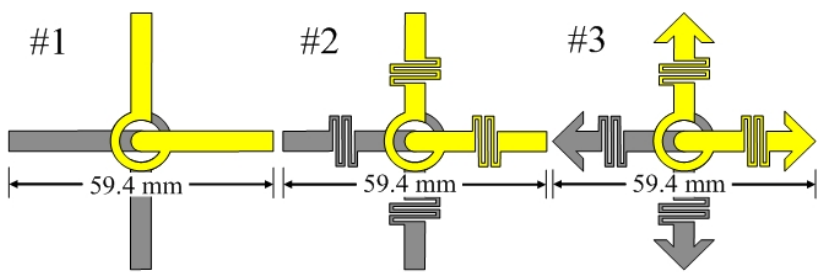

(a)

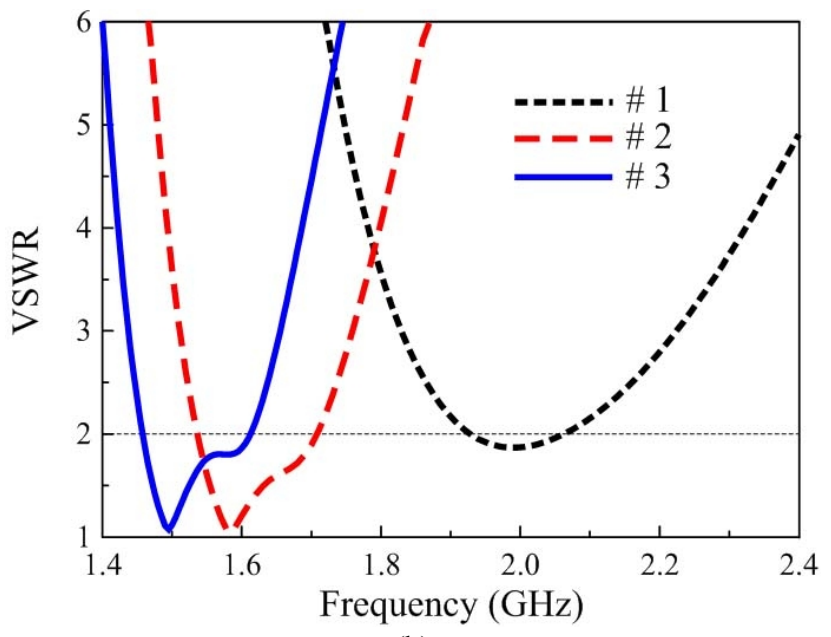

(b)

Fig. 2. (a) Dipole-length reduction process and (b) VSWR as a function of frequency for different crossed dipoles.

initial design (design \#1) was two straight dipoles crossed through the vacant-quarter printed ring. Four meander lines were then symmetrically inserted into the dipole arms (design \#2). Finally, each dipole end was shaped like an arrowhead (design \#3). Note that all design \#1 3 were built on both sides of the $42 \times 42 \mathrm{~mm}$ Rogers RO4003 substrate $\left(\varepsilon_{r}=3.38, \tan \delta=0.0027\right.$, and thickness $=0.2032 \mathrm{~mm}$ ) and suspended at $H=30 \mathrm{~mm}$ from the bottom of the $90 \times 90 \mathrm{~mm}$ cavity-backed reflector. The above three structures were simulated using HFSS software and VSWRs were given in Fig. 2(b). From the simulations, the design $\# 1$ yielded the lowest resonant frequency at around $2 \mathrm{GHz}$ and no resonance near the GPS band of $1.57 \mathrm{GHz}$. As shown in Fig. 2(b), design \#2 yielded two resonances near 1.58 and $1.67 \mathrm{GHz}$. The arrowhead dipole (design \#3) yielded lower resonant frequencies when compared with the corresponding values for design \#2. Additionally, HFSS calculations showed that the thinner trace width $\left(w_{i}\right)$, the larger gap size $\left(g_{i}\right)$, and the larger arrowhead produce lower resonances, but the reduction in size is accompanied by degradation of the 3-dB AR bandwidth. These results indicate that the compact size of the primary radiation elements $(42 \times 42$ $\mathrm{mm} \sim 0.22 \lambda_{0} \times 0.22 \lambda_{0}$ at $1.575 \mathrm{GHz}$ ) is attained by the use of meander lines in the dipole arm and the arrowhead-shaped trace at its end. 


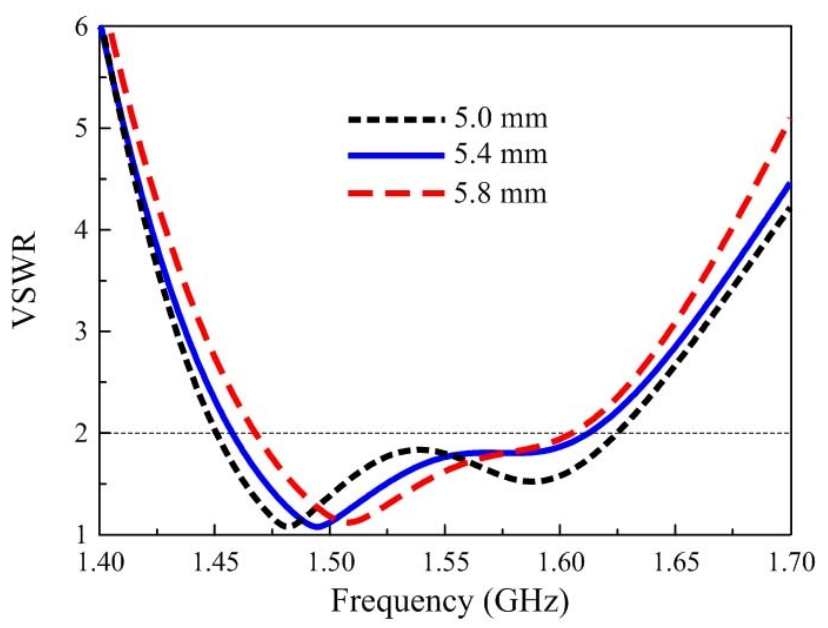

(a)

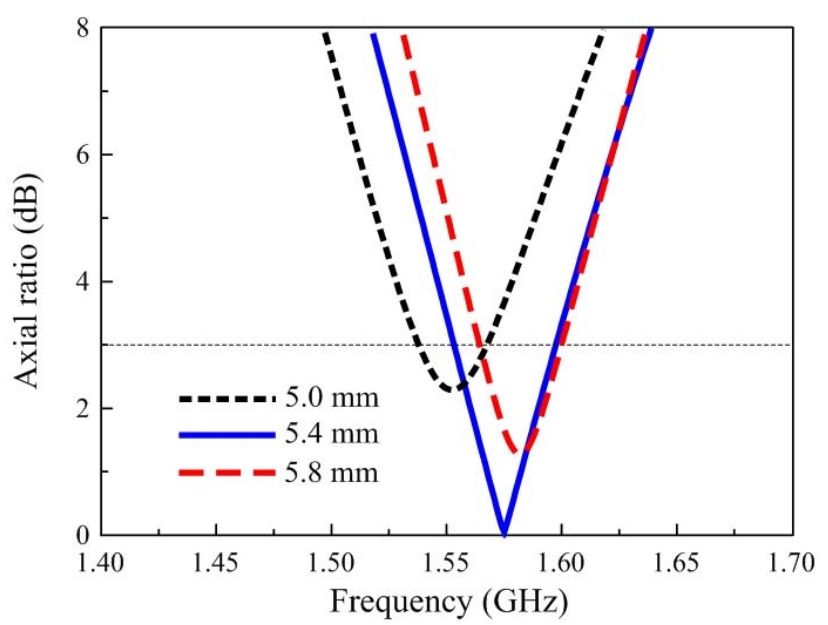

(b)

Fig. 3. (a) VSWR and (b) AR as a function of frequency for different radii of the vacant-quarter printed ring $\left(R_{i}\right)$.

The vacant-quarter printed ring was not only employed to produce CP radiation, but it also allowed the broadband characteristic. These capacities are observed in Figs. 3 and 4, which show simulated VSWR and AR of the antenna as a function of frequency for different radii $\left(R_{i}\right)$ and widths $\left(W_{r}\right)$ of the printed ring. As shown in Fig. 3, an increase of $R_{i}$ slightly affected VSWR, while the CP center frequency increased. Here, the CP center frequency was defined as the frequency with minimum AR. In addition, $R_{i}=5.4 \mathrm{~mm}$ offered the optimal $\mathrm{CP}$ radiation in terms of the widest $3-\mathrm{dB}$ AR bandwidth and minimum AR. In Fig. 4, as $w_{i}$ was increased from $0.5 \mathrm{~mm}$ to $1.1 \mathrm{~mm}$ in increments of $0.3 \mathrm{~mm}$, the impedance matching bandwidth narrowed concomitantly, while the CP center frequency decreased. The HFSS simulations indicated that the antenna with $W_{r}<0.5 \mathrm{~mm}$ yielded $\mathrm{AR}>3 \mathrm{~dB}$ and $W_{r}=0.8 \mathrm{~mm}$ offered the optimized results in terms of broad impedance matching and

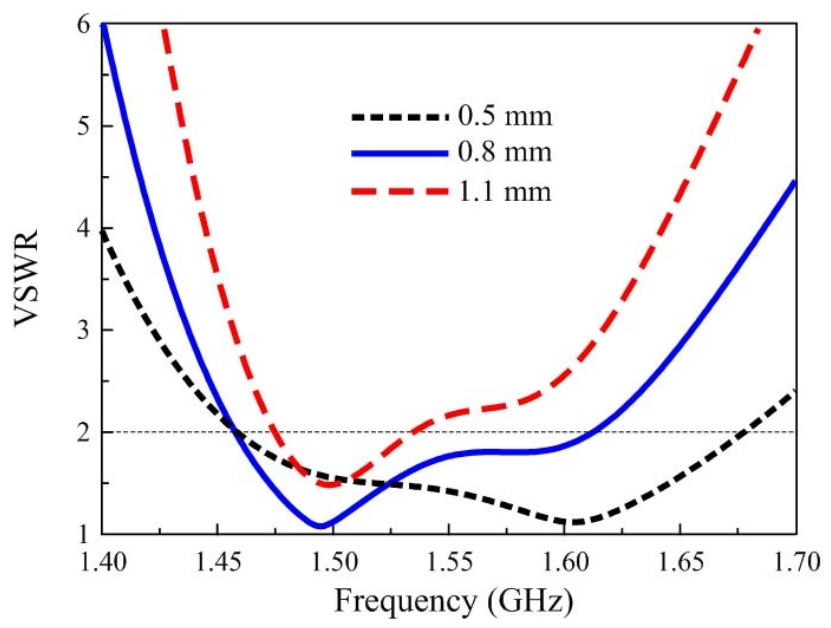

(a)

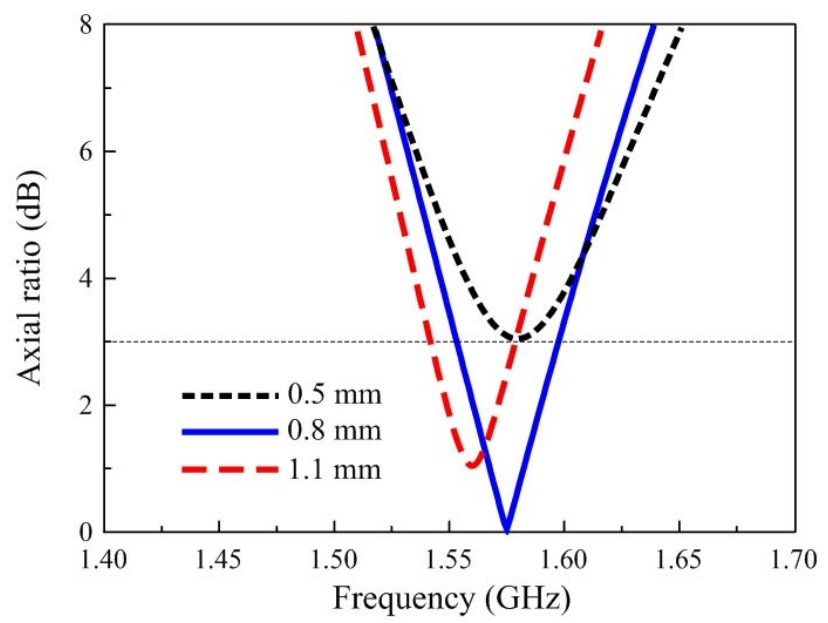

(b)

Fig. 4. (a) VSWR and (b) AR as a function of frequency for different widths of the vacant-quarter printed ring $\left(W_{r}\right)$.

3-dB AR bandwidths at the GPS L1 band.

The proposed antenna employs meander lines to reduce the dipole length. The trace width of the meander lines $\left(w_{i}\right)$ is much smaller than the width of the dipole $\left(W_{b}\right)$, so the current accumulates to an extreme degree on the meander line. This can be clearly seen in Fig. 5, which displays the simulated current distribution on the crossed dipoles at $1.575 \mathrm{GHz}$ with two phase angles of $0^{\circ}$ and $90^{\circ}$. It also explains the CP behavior of the proposed antenna; the vertical dipole arms worked at the phase angle of $0^{\circ}$ and the horizontally oriented dipole arms worked at the phase angle of $90^{\circ}$. The arrangement of the meander lines has a significant effect on the antenna characteristics. Accordingly, the effects of the starting point of meander lines $\left(L_{b}\right)$ on VSWR and AR of the antenna were studied and are shown in Fig. 6. As $L_{b}$ was varied from $9 \mathrm{~mm}$ to $13 \mathrm{~mm}$ in increments of $2 \mathrm{~mm}$, the resonances increased [Fig. 6(a)] and the CP 


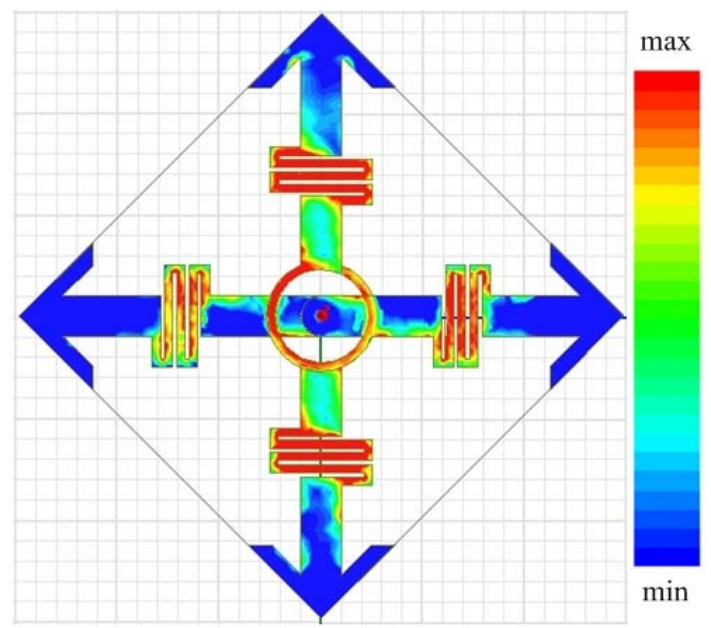

(a) $0^{\circ}$

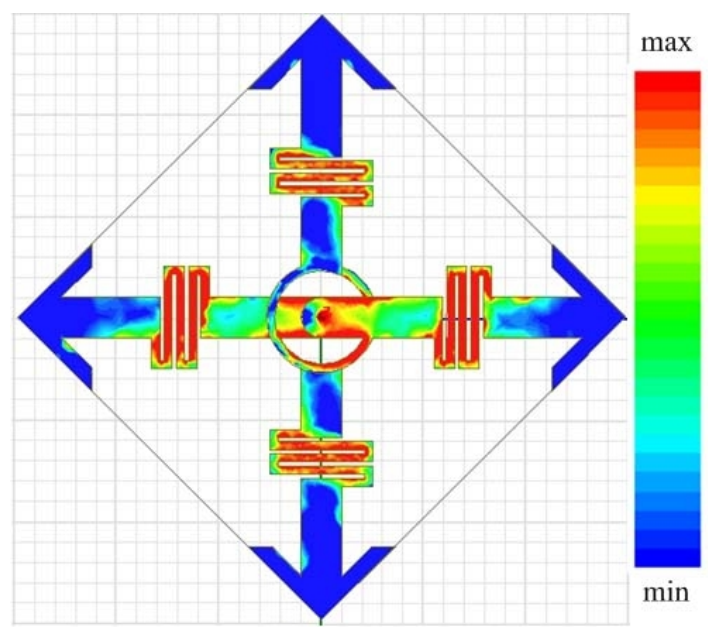

(b) $90^{\circ}$

Fig. 5. Simulated current distribution on the crossed arrowhead-dipoles at $1.575 \mathrm{GHz}$ for two phase angles.

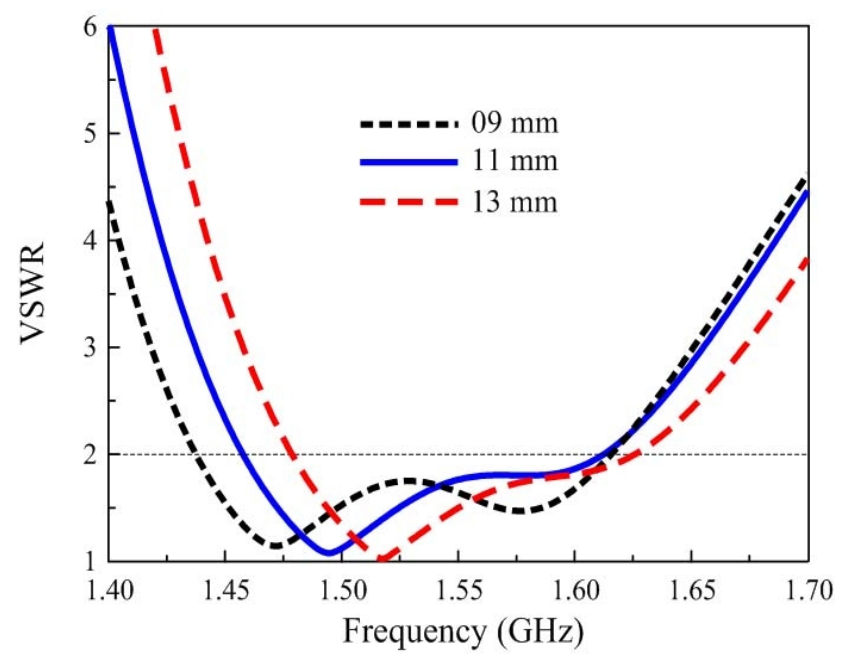

(a)

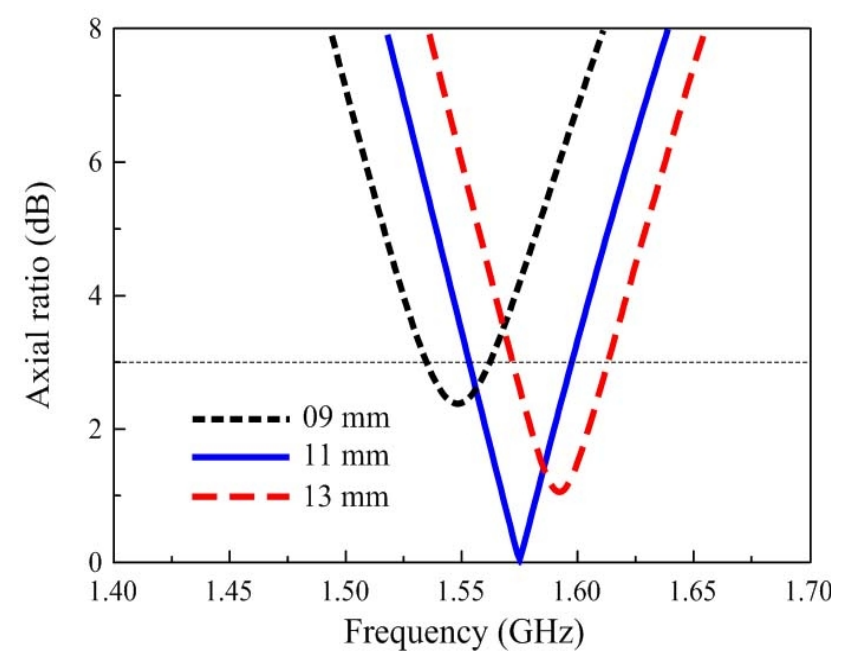

(b)

Fig. 6. (a) VSWR and (b) AR as a function of frequency for different starting points $\left(L_{b}\right)$ of the printed inductor. center frequency also increased [Fig. 6(b)]. This result indicates that the operating frequency of the antenna can be controlled by adjusting the starting-point of the meander lines.

\section{Measured and Simulated Results}

The composite cavity-backed crossed dipole antenna was fabricated and measured. The planar crossed arrowhead dipoles were built on both sides of a Rogers RO4003 substrate with a copper thickness of $20 \mu \mathrm{m}$ via a standard etching technology. The cavity-backed reflector was constructed using five copper plates (one $90 \times 90$ $\mathrm{mm}$ and four $90 \times 30 \mathrm{~mm}$ ) having a thickness of $0.2 \mathrm{~mm}$. A sample of the proposed antenna [Fig. 7(a)] was used for input impedance and radiation pattern measurements. The measured and simulated VSWR of the proposed antenna are shown in Fig. 7(b). The measured bandwidth was $1.450 \sim 1.656 \mathrm{GHz}$ for $\operatorname{VSWR}<2$, while the simulated bandwidth was $1.458 \sim 1.613 \mathrm{GHz}$. A slight discrepancy between measurement and simulation could be attributed to the misalignment of the dipole-arms on the different sides of the substrate. The simulated and measured ARs of the proposed antenna are also shown in Fig. 7(b) and indicate a good agreement between the two. The measured 3-dB AR bandwidth was 1.555 $1.605 \mathrm{GHz}$ with the $\mathrm{CP}$ center frequency of $1.580 \mathrm{GHz}$ (AR of $0.96 \mathrm{~dB}$ ) while the simulated $3-\mathrm{dB}$ axial ratio bandwidth was $1.554 \sim 1.597 \mathrm{GHz}$ with the $\mathrm{CP}$ center frequency of $1.575 \mathrm{GHz}$ (AR of $0.05 \mathrm{~dB}$ ).

Fig. 8 shows the $1.575 \mathrm{GHz}$ radiation patterns of the antenna with RHCP, symmetrical profile, and wide beamwidth in both $\mathrm{x}-\mathrm{z}$ and $\mathrm{y}-\mathrm{z}$ planes. The RHCP, in particular, can be interchanged with the LHCP by reversing the vacant-quarter printed ring. The measurements yield- 


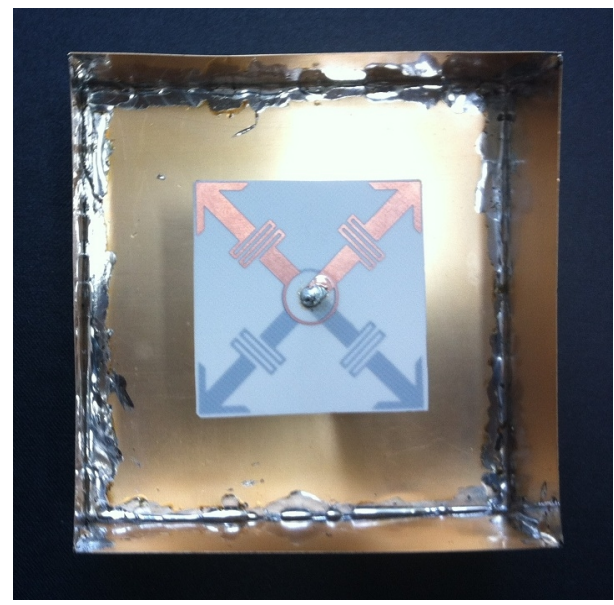

(a)

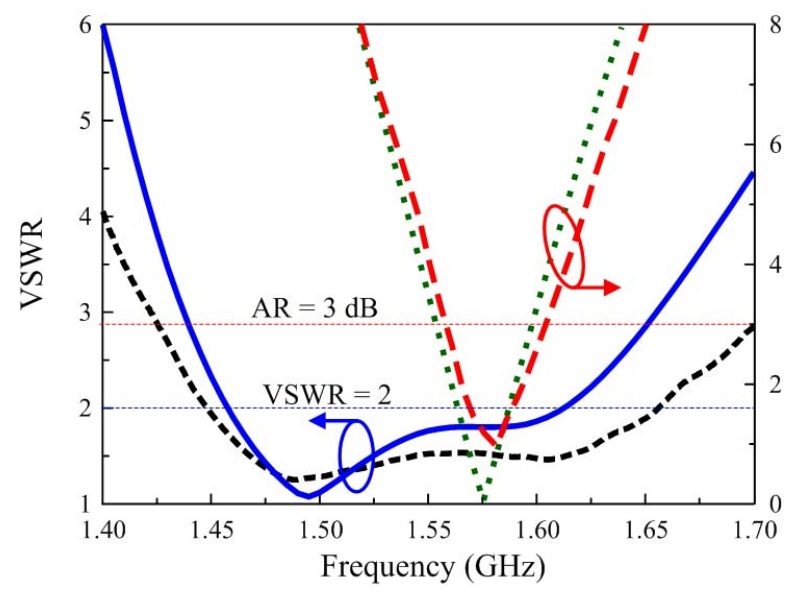

(b)

Fig. 7. (a) Fabricated antenna and (b) simulation and measurement of VSWR and AR for the proposed antenna. --1.. VSWR measurement; — VSWR

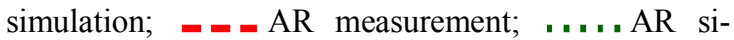
mulation.

ed a gain of $7 \mathrm{dBic}$, a front-to-back ratio of $27 \mathrm{~dB}$, and $3-\mathrm{dB}$ beamwidths of $104^{\circ}$ and $105^{\circ}$ in the $\mathrm{x}-\mathrm{z}$ and $\mathrm{y}-\mathrm{z}$ planes, respectively. Fig. 9 shows the simulated and measured AR of the antenna versus theta angle at 1.575 GHz. The measured 3-dB AR beamwidths were $130^{\circ}$ and $132^{\circ}$ in the $\mathrm{x}-\mathrm{z}$ and $\mathrm{y}-\mathrm{z}$ planes, respectively. The simulated beamwidth for $3-\mathrm{dB}$ AR were $145^{\circ}$ and $148^{\circ}$ in the $\mathrm{x}-\mathrm{z}$ and $\mathrm{y}-\mathrm{z}$ planes, respectively. The $\mathrm{CP}$ radiation beamwidth was slightly narrower for the measurements than for the simulations. This could be attributed to the substrate bending effects.

\section{Conclusion}

A CP composite crossed dipole was introduced for use in GPS with broadband characteristics $(1.45-1.65 \mathrm{GHz}$ for $\mathrm{VSWR}<2$ and $1.555 \sim 1.605$ for $\mathrm{AR}<3$ ) and wide beamwidth radiation $\left(>100^{\circ}\right.$ for $3-\mathrm{dB}$ beamwidth and $>$

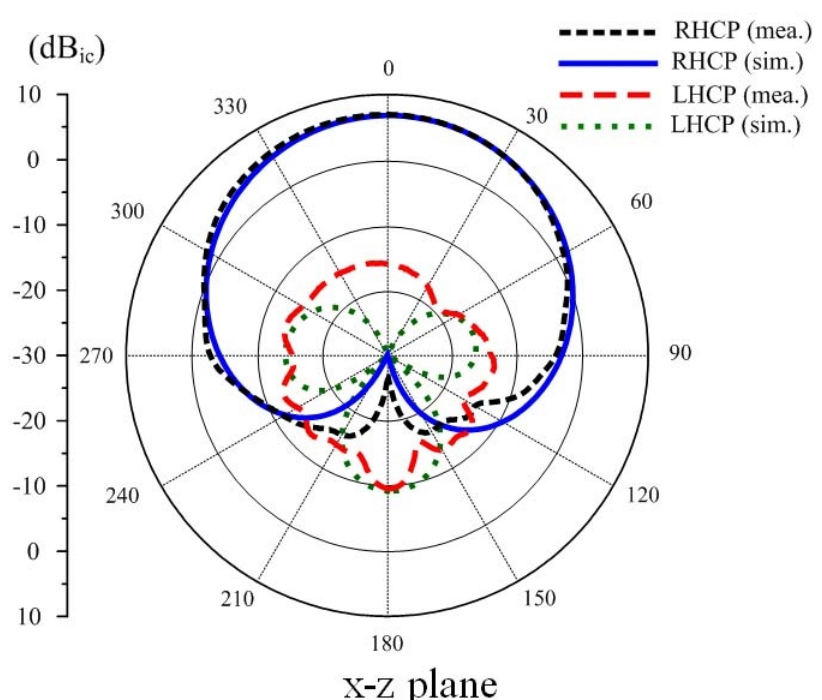

(a)

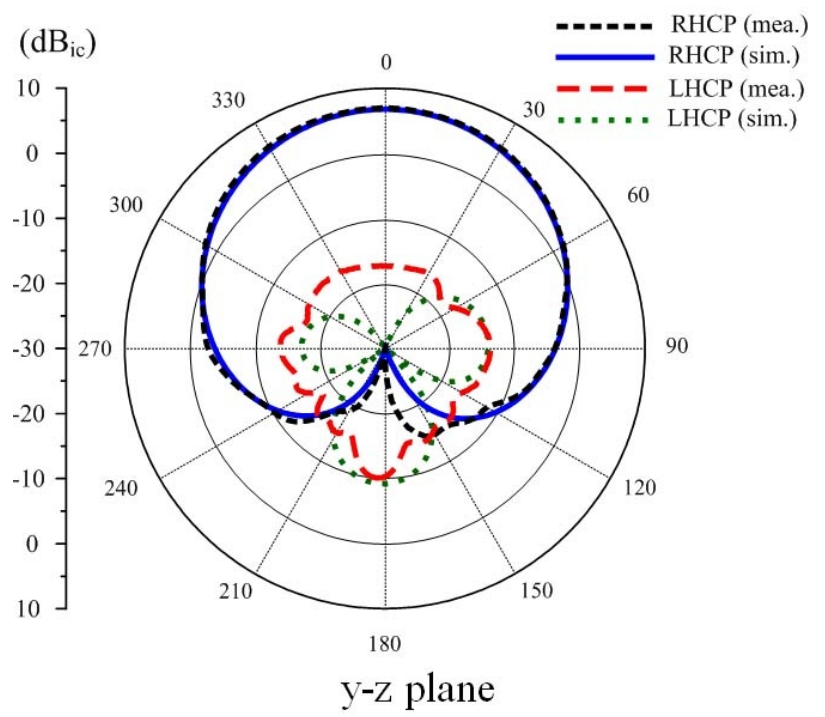

(b)

Fig. 8. Radiation patterns of the antenna at $1.575 \mathrm{GHz}$.

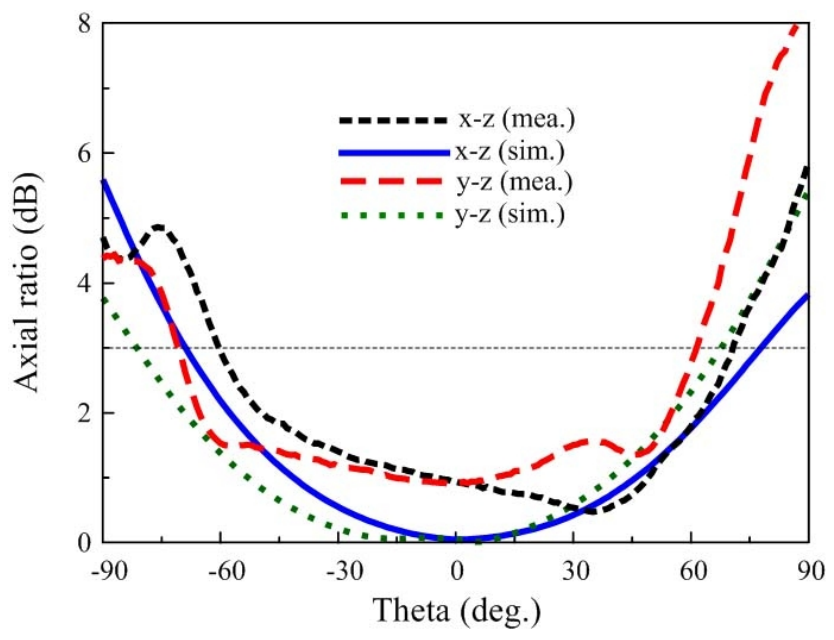

Fig. 9. AR versus theta angle at $1.575 \mathrm{GHz}$. 
$130^{\circ}$ for $3 \mathrm{~dB}$ AR beamwidth). A vacant-quarter printed ring was used as the $90^{\circ}$ phase delay line to produce $\mathrm{CP}$ radiation. Arrowhead dipoles and meander lines were employed for a significant reduction of the radiator sizes. The cavity-backed reflector was utilized not only to achieve a unidirectional radiation pattern but also improve the $\mathrm{CP}$ radiation beamwidth. The proposed wide beamwidth antenna can be widely applied to GPS purposes, as well as to satellite communications.

\section{References}

[1] P. Enge, P. Misra, "Special issue on global positioning systems," Proc. IEEE, vol. 87, no. 1, pp. 3-15, Jan. 1999.

[2] K. Lam, K. Luk, K. Lee, H. Wong, and K. Ng, "Small circularly polarized U-slot wideband patch antenna," IEEE Antenna Wireless Propagat. Lett., vol. 10, pp. 87-90, 2011.

[3] S. Dey, S. Chebolu, R. Mittra, I. Park, T. Kobayashi, and M Itoh, "A compact microstrip antenna for CP," Antennas and Propagation Society International Symposium, AP-S. Digest, pp. 982-985, Jun. 1995.

[4] P. Jin, C. Lin, and R. W. Ziolkowski, "Multifunctional, electrically small, planar near-field resonant parasitic antennas," IEEE Antennas Wireless Propagat. Lett., vol. 11, pp. 200-204, 2012.

[5] P. Jin, R. W. Ziolkowski, "High directivity, electrically small, low-profile, near-field resonant parasitic antennas," IEEE Antennas Wireless Propagat. Lett.,

\section{Son Xuat Ta}

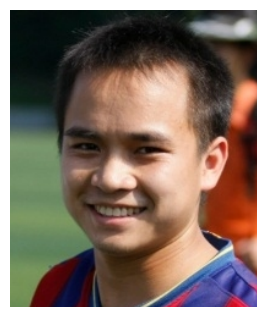

received the B.S degree in electronics and telecommunications from Hanoi University of Science and Technology, Hanoi, Vietnam in 2008. He is currently studying a Ph.D. course in the Department of Electrical and Computer Engineering, Ajou University, Suwon, Korea. His researches are focused on the wideband, multiband, and UWB antennas for next generation wireless communication systems. vol. 11, pp. 305-309, 2012.

[6] J. Baik, T. Lee, S. Pyo, S. Han, J. Jeong, and Y. Kim, "Broadband circularly crossed dipole with parasitic loop resonators and its array," IEEE Trans. Antennas Propagat., vol. 59, no. 1, pp. 80-88, Jan. 2011.

[7] W. Lee, K. Oh, and J. Yu, "A wideband circularly polarized pinwheel-shaped planar monopole antenna for wireless applications," J. Electro-Mag. Eng. Sci., vol. 12, no. 2, pp. 155-160, Jun. 2012.

[8] C. W. Su, S. K. Huang, and C. H. Lee, "CP microstrip antenna with wide beamwidth for GPS band application," Electron. Lett., vol. 43 no. 20, pp. 10621063, Sep. 2007.

[9] Z. Chen, W. Toh, and X. Qing, "A microstrip patch antenna with broadened beamwidth," Microwave Opt. Technol. Lett., vol. 50, no. 7, pp. 1885-1888, Jul. 2008.

[10] J. Ouyang, F. Yang, S. Yang, and Z. Nie, "A novel E-shape radiation pattern reconfigurable microstrip antenna for broadband, wide-beam, high-gain applications," Microwave Opt. Technol. Lett., vol. 50, no. 8, pp. 2052-2054, Aug. 2008.

[11] Z. Duan, S. Qu, Y. Wu, and J. Zhang, "Wide bandwidth and broad beamwidth microstrip patch antenna," Electron. Lett., vol. 45, no. 5, pp. 249-250, 2009.

[12] C. Wu, L. Han, F. Yang, L. Wang, and P. Yang, "Broad beamwidth circular polarisation antenna: microstrip-monopole antenna," Electron. Lett., vol. 48, no. 19, 1176-1178, 2012.
Jae Jin Han

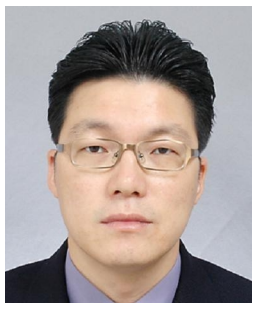

received the B.S degree in electronics engineering from Korea Polytechnic University, Siheung, Korea in 2006, and the M. $\mathrm{S}$ degree in electrical engineering from Ajou University, Suwon, Korea in 2008. He is currently studying a Ph.D course in the Department of Electrical and Computer Engineering, Ajou University, Suwon, Korea and working for R\&D division of DANAM Systems Inc., Anyang, Korea. His researches are focused on the antennas and RF devices. 


\section{Ikmo Park}

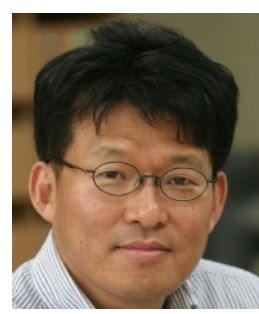

received the B.S. degree in electrical engineering from State University of New York, USA in 1984. He received the M.S. and $\mathrm{Ph} . \mathrm{D}$. degrees in electrical and computer engineering from University of Illinois, USA in 1989 and 1994, respectively. From 1994 to 1996, he worked for LG Corporate Institute of Technology. Since 1996, he has been a professor in Ajou University, Suwon, Korea. His research interests include the design and analysis terahertz and microwave passive devices and antennas. 